\title{
A DESCONSTRUÇÃO DA DIVERSIDADE POR PADRÕES: PONDERAÇÕES ENTRE A IGUALDADE E A DIFERENÇA
}

\section{Andréia Garcia Martin ${ }^{1}$ Juliana Izar Soares da Fonseca Segalla ${ }^{2}$}

Resumo: O presente estudo tem como escopo trazer uma reflexão sobre o estabelecimento de padrões e o conceito de normalidade em relação aos seres humanos. Para tanto, trata do direito à igualdade e do direito à diferença enquanto tradutores da dignidade humana e demonstra que é diversidade e característica da humanidade e que, portanto, é preciso fomentar sua valorização e respeito. Por fim, destacamos a importância da escola na construção/desconstrução de paradigmas que desconsideram essa natureza humana.

Palavras-chave: Padrões; Normalidade; Dignidade humana; Diversidade; Escola.

\section{DEDUCTION OF DIVERSITY BY PATTERNS: WEIGHTINGS OF EQUALITY AND DIFFERENCE}

Abstract: The present study aims to reflect on the establishment of standards and the concept of normality in relation to human beings. To this end, it deals with the right to equality and the right to difference as translators of human dignity and demonstrates that it is a diversity and characteristic of humanity and that, therefore, it is necessary to promote its appreciation and respect. Finally, we emphasize the importance of the school in the construction/deconstruction of paradigms that disregard this human nature.

Keywords: Standards; Normality; Human dignity; Diversity; School.

\section{"A maior deficiência não está no corpo do deficiente físico, mas, na alma do preconceituoso."} Sebastião Barros Travassos

\section{INTRODUÇÃO}

\footnotetext{
${ }^{1}$ Doutora em Direito Constitucional pela Pontifícia Universidade Católica de São Paulo/SP (PUC/SP). Mestra em Direito, pela Instituição Toledo de Ensino em Bauru (ITE). Especialista em Justiça Constitucional pela Universidade de Pisa (Itália). Bacharela em Direito pelo Centro Universitário de São José do Rio Preto/SP (2002). Atualmente é Professora do instituto Municipal de Educação Superior (IMES-FAFICA) de Catanduva/SP e da Universidade do Estado de Minas Gerais - Unidade Frutal. Líder do Grupo de Pesquisa, certificado pelo CNPQ, "IRIS" - Igualdade, Reconhecimento e Inclusão Social. Advogada. E-mail: andreiagarciamartin@gmail.com. Lattes: http://lattes.cnpq.br/5843968752917552.

2 Doutora em Direito Constitucional pela Pontifícia Universidade Católica de São Paulo/SP (PUC/SP). Mestra em Direito, pela Instituição Toledo de Ensino em Bauru (ITE). Pesquisadora e Avaliadora do CONPEDI (Conselho Nacional de Pesquisa e Pós-Graduação em Direito). Advogada. E-mail: juizarsegalla@hotmail.com. Lattes: http:/lattes.cnpq.br/7574932168844402.
} 
A estruturação das sociedades ocidentais capitalistas, ocorrida a partir dos fins do século XIX, visando consolidarem uma cultura de desenvolvimento das atividades industriais, encamparam, desde os primeiros modelos da atividade industrial, a delimitação de padrões com a finalidade de se alcançar uma produção em larga escala.

Assim, constatamos que, em razão desta finalidade, tudo que envolvia diretamente a produção industrial, necessitava passar por uma espécie de filtro que classificava como apto ou inapto à produção. Tal classificação servia para matérias-primas, insumos e, inclusive, trabalhadores.

Dessa forma, aqueles que eram categorizados como incapazes de desenvolverem as atividades laborativas em franca produção, quedavam-se à margem da linha imaginária traçada. Estabeleceram-se padrões para definir o que seria o produtivo e o improdutivo, o capaz e o incapaz. Via de consequência, esse padrão, com sustentação nas ciências médicas, foram imputados às pessoas com deficiência visando sua reabilitação ao trabalho. Então, por possuírem uma diferença funcional, eram considerados inválidos ou incapazes, não se enquadrando no padrão de normalidade definida para a produção.

A maneira como as diversas instituições estatais lidavam com o ser humano e suas relações em sociedade, tais como educação e trabalho, era (e ainda é) fundada no estabelecimento de modelos, padrões, molduras nas quais todos deveriam (devem) se encaixar. Essa prática criou nitidamente uma linha divisória entre os que preenchiam a moldura e os Outros que não a preenchiam. Tal moldura foi impulsionada, sob a ótica do sistema jurídico, pela igualdade formal, sustentada na ideia de que todos são iguais perante a lei.

Diante desse contexto, a presente pesquisa busca demonstrar que a delimitação de padrões para definir e categorizar os seres humanos entre normais ou anormais, ao ser difundida de maneira ampla na sociedade, tem a capacidade de desconstruir a ideia de diferença ínsita aos seres humanos, negando o reconhecimento da diversidade.

Ora, ao se atribuir um padrão de pessoas tidas como normais, cria-se uma ideia de que ser normal é o "correto" e ser "anormal” é errado. Assim, todos aqueles que se encontram abaixo da classificação de normalidade, seriam considerados anormais, fora dos padrões estabelecidos. 
Destarte, vislumbramos por esta pesquisa que é premente a observância e garantia do direito à diferença, com o consequente distanciamento dos discursos que aproximam os padrões de normalidade da falsa ideia de homogeneidade, pois ao permearem o senso comum inferiorizam minorias e grupos vulneráveis ( $v . g$. as pessoas com deficiência, negros, pessoas com marcas estéticas perceptíveis como cicatrizes, doenças de pele etc.), ignorando o reconhecimento do direito à diferença enquanto garantidor da dignidade humana, que abarca o respeito à individualidade.

Demonstraremos que toda vez que se deseja "padronizar o ser humano" ocorrerá um desrespeito à própria natureza da espécie, pois a diversidade é característica da humanidade.

Ademais, para atingir o objetivo proposto, indaga-se sobre o que é ser normal e analisa-se o conceito de normalidade à luz da condição humana.

Por fim, registra-se o papel da escola enquanto agente de transformação social e se reflete sobre a contribuição da escola para a construção/desconstrução de padrões para seres humanos.

A pesquisa será fundada no método de procedimento histórico, comparativo e hermenêutico, como método de raciocínio o dedutivo, já que utilizaremos de uma disposição geral para aplicá-la em casos específicos, e por tipo de pesquisa a bibliográfica.

\section{O DIREITO À IGUALDADE E O DIREITO À DIFERENÇA}

O direito à igualdade permeou a gênese das sociedades desde o advento do Estado de Direito. Na história do constitucionalismo no mundo observamos que a igualdade, ora tida apenas como direito, ora como direito e princípio fundamental do Estado, vai se modificando com o passar dos tempos, ganhando formas diferenciadas.

A igualdade enquanto meta do Estado, valor ideológico e construção filosófica, é tema que sempre possuiu espaço para debate, refletindo nos mais variados discursos com o fito de dar-lhes legitimidade.

Para este trabalho é preciso, pois, que aventemos a igualdade como um dos direitos fundamentais mais básicos do ser humano, tratando-a como o próprio direito à diferença. Para chegarmos a tal patamar, comporta-nos realizarmos um breve panorama histórico de seu desenvolvimento para chegarmos ao seu dimensionamento na atualidade. 
Eis que, tal digressão histórica envolve os questionamentos que cercam a afirmação de que "todos somos iguais". Sob tal ideia, Bobbio aduz que: “"uma das máximas muito proclamadas no pensamento político ocidental é a de que 'todos os homens são ou nascem iguais', mas o que atribui uma conotação positiva a essa enunciação não é a igualdade, 'mas a extensão da igualdade a todo"”. (BOBBIO, 1997, p. 23).

Em outras palavras, o que promove a ideia de igualdade é a observância de que todos somos iguais em humanidade, mas não em nossas identidades.

A Declaração Universal dos Direitos Humanos, de 1948, anunciava em seu primeiro dispositivo que "todos os homens são iguais em dignidade e direitos", trata-se não da ideia de que nossos direitos e dignidade são iguais, mas que cada um de nós possui sua própria dignidade e seus próprios direitos.

Entretanto, ao longo da História, a igualdade nem sempre foi vista dessa maneira, sendo por vezes desapercebida, servindo para a sustentação de grandes injustiças, quando observada, por exemplo, apenas sob o viés formal, ou ainda quando desconsiderada sua faceta de direito à diferença. Sob tais concepções, da História captamos variações impingidas em nome da igualdade.

Com o advento do Estado moderno, no século XVIII, a igualdade era reconhecida apenas formalmente, visando promover a igual submissão de todos à lei (era a conhecida “igualdade perante a lei”). Podemos dizer que, em razão da ruptura do Estado Absolutista, num primeiro momento, se fazia relevante a defesa dessa igualdade formal, com o objetivo de se evitar que os privilégios de antes estivessem ainda presentes.

Já no Estado de Direito Social, nas duas primeiras décadas do século XX, sob os marcos da Constituição Mexicana, de 1917, e Constituição Alemã, da República de Weimar, de 1919, a igualdade formal percebe-se insuficiente, ganhando nova roupagem, para então abranger a função de promover os direitos sociais de forma a equilibrar a balança social, ou seja, a igualdade tinha de dar a todos as mesmas oportunidades (tem início, ao menos no plano abstrato, a ideia de igualdade de oportunidades, de justiça social). Trata-se do reflexo da máxima aristotélica: "tratar iguais, igualmente; desiguais, desigualmente, na medida de sua desigualdade".

Contudo, evidentemente, surgem diversos questionamentos desta máxima, quais sejam: quem são os iguais? Quem são os diferentes? Qual é a medida da desigualdade? De 
que forma deve ser este tratamento igual ou diferente? Quais os parâmetros para diferenciar o tratamento?

Tais questionamentos, evidentemente, não podem ser respondidos destacados da realidade em que estavam inseridos à época, o que é certo é que a definição de iguais, desiguais, e os parâmetros para diferenciar os tratamentos e enquadra-los abaixo ou acima da classificação, dependia de decisões políticas de poder, fundadas em valores e culturas dominantes em certa época. Em síntese, os padrões que hierarquizavam os membros de uma sociedade refletiam as ideologias preponderantes dos "donos do poder", e desta forma, por vezes, apresentavam-se completamente desconectados da realidade fática.

Ademais, convém asseverarmos que, se a igualdade material for observada apenas sob a circunstância de outorgar oportunidades, sua caracterização volta-se a políticas de redistribuição, em que se consigna unicamente a desigualdade entre os membros da sociedade, como motivo para promover políticas de equilíbrio social e econômico. Destarte, fazia-se necessário a observância de outra faceta desta igualdade, qual seja: a igualdade material fundada no reconhecimento da diferença ${ }^{3}$.

Diante do desdobramento das duas faces da igualdade que dispusemos acima, quais sejam, a formal e a material, ressaltamos que a radicalização de ambas resulta em graves problemas quando aplicadas. Ou seja, quando tratamos da concepção de que "todos somos iguais" (igualdade formal) institui-se um universalismo anti-diferencialista que se gere pela negação das diferenças. Por outro lado, sob a concepção de tratar desiguais de forma desigual, valemo-nos do universalismo diferencialista ensejando a absolutização das diferenças. Neste sentido, Boaventura de Sousa Santos, aduz que:

\begin{abstract}
A negação das diferenças opera segundo a norma da homogeneização que impede a comparação pela destruição dos termos de comparação. A absolutização das diferenças opera segundo a norma do relativismo que torna incomparáveis as diferenças pela ausência de critérios transculturais. Quer um, quer outro processo permitem a aplicação de critérios abstractos de normalização sempre baseados numa diferença que tem poder social para negar todas as demais ou para as declarar incomparáveis e, portanto, inassimiláveis. (SANTOS, 1999).
\end{abstract}

\footnotetext{
${ }^{3}$ Neste sentido, é o entendimento de Flavia Piovesan, segundo a qual: "Destacam-se, assim, três vertentes no que tange à concepção da igualdade: a) a igualdade formal, reduzida à fórmula "todos são iguais perante a lei" ( o que a seu tempo foi crucial para a abolição dos privilégios); b) igualdade material, correspondente ao ideal de justiça social e distributiva (igualdade orientada pelo critério sócio-econômico); e c) a igualdade material, correspondente ao ideal de justiça enquanto reconhecimento de identidades (igualdade orientada pelos critérios de gênero, orientação sexual, idade, raça, etnia e demais critérios)"." (PIOVESAN, Flavia. Igualdade, Diferença e Direitos Humanos: Perspectiva Global e Regional. SARMENTO, Daniel; IKAWA, Daniela; PIOVESAN, Flávia (Coord.). Igualdade, Diferença e Direitos Humanos. Rio de Janeiro: Lumen Juris, 2010, p. 49).
}

Revista de Sociologia, Antropologia e Cultura Jurídica | e-ISSN: 2526-0251 | Porto Alegre | v. 4 | n. 2 |

p. $01-28$ | Jul/Dez. 2018 
Sob tais ideias, temos a dimensão de quão perniciosa era a radicalização das atuações estatais em nome da igualdade. Ora, tanto a universalização anti-diferencialista como a absolutização das diferenças fomentavam a formação de padrões para controlá-los, sendo que ambos provocavam o mesmo efeito, qual seja: evitavam a garantia do direito a diferença.

Esse terceiro desdobramento da igualdade pode ser evidenciado na célebre citação do autor português Boaventura de Sousa Santos: "temos o direito a ser iguais, sempre que a diferença nos inferioriza; temos o direito de ser diferentes sempre que a igualdade nos descaracteriza". E continua explicando que é imprescindível "a necessidade de uma igualdade que reconheça as diferenças e de uma diferença que não produza, alimente ou reproduza as desigualdades." (SANTOS, 2006, p. 462).

Com efeito, será necessário se assegurar a igualdade quando as diferenças fáticas promoverem a discriminação negativa; por outro lado, se faz coerente garantir a diferença quando a igualização provocar a ruptura da identidade inerente a cada uma das pessoas. Daí que se constatando a terceira caracterização da igualdade, que é o reconhecimento da diferença fundado na diversidade humana, tende a promover a dignidade humana.

Vera Candau, analisando ainda a terceira faceta da igualdade, aponta que: "parece que hoje o centro de interesse se deslocou. Quando digo que houve um deslocamento, não estou querendo dizer que se nega a igualdade, mas que se coloca muito mais em evidência o tema da diferença". (CANDAU, 2008, p. 46).

Esta evidência tem sentido quando notamos que em razão de se submeter todos à lei, ou de garantir igual oportunidades, esqueceu-se as diferenças inerentes aos seres humanos e, consequentemente, criou-se fórmulas, padrões para definir ou classificar a atribuição dessa igualdade.

Neste sentido, Antonio Flavio Pierucci, afiança que a fórmula da igualdade necessita afirmar que "somos também diferentes de direito", tratando-se do "direito à diferença, o direito à diferença cultural, o direito de ser, sendo diferente". 5 (PIERUCCI, 1999, p. 7).

\footnotetext{
${ }^{4}$ Ademais, complementa o citado autor que "há que reconhecer que nem toda diferença é inferiorizadora". (SANTOS, 2006, p. 462), pelo contrário, as diferenças devem ser preservadas com o escopo de se garantir a identidades e singularidades que compõem os seres humanos.

${ }^{5}$ Convém anotarmos, no entanto, que a definição dos padrões de igualdade/desigualdade, de inclusão/exclusão, normal/anormal decorrem de definições que pretendiam estabelecer um homem ideal para poder melhor ser dominado, neste sentido: "os enunciados dos sujeitos demonstram a utilização de argumentos da biologia e da ciência para justificar uma igualdade entre os homens. Mas essa suposta igualdade está, - ela mesma, inscrita na representação e no poder. É
} 
O autor supramencionado continua:

The right to bed different! é como se diz em inglês o direito à diferença. Não queremos mais igualdade, parece. Ou a queremos menos. Motiva-nos muito mais, em nossas demandas, em nossa conduta, em nossas expectativas de futuro e projetos de vida compartilhada, o direito de sermos pessoal e coletivamente diferentes uns dos outros. (PIERUCCI, 1999, p. 7).

O clamor pelo direito à diferença não significa em nos afastarmos do pacto social no qual todos nos submetemos, nos isentando de cumprir a lei, pelo contrário, desejamos reafirmar a subserviência aos parâmetros do direito, pelo próprio reconhecimento do direito à diferença.

Notamos, evidentemente, que estamos em um paradoxo. De um lado, um clamor, o chamado para preservar, garantir e tutelar a diferença. Por outro, sua completa desconsideração, vez que a diferença não cabe no padrão, na norma, escapando à acomodação da moldura predefinida pelo Estado. Ser diferente é exigir que esta diferença seja tutelada pelo Estado é situar-se na fora dos padrões de normalidade criados pelos poderes dominantes, para definir um ser humano como adequado para participar da sociedade.

Inegável que por muito tempo se desconsiderou a própria necessidade de se preservar a diferença, já que ser diferente era sinônimo de possuir menos direitos, menos respeito e dignidade, "um ser esvaziado mesmo de qualquer dignidade, um ser descartável, um ser supérfluo, objeto de compra e venda (como na escravidão) ou de campos de extermínio (como no nazismo)." (PIOVESAN, 2010, p. 48).

Em síntese, a classificação dos seres humanos sob certos parâmetros, seja igualandoos ou os diferenciando provocaram as maiores distorções que a humanidade experimentou.

Outrossim, o estabelecimento de padrões, de linhas divisórias entre os seres humanos como se fosse algo natural, com a consequente difusão dessa naturalização da normalidade, enseja a completa desconsideração da diferença como inerente ao ser humano, e a prevalência de uma ideia de superioridade/inferioridade inexistente. ${ }^{6}$ Sob a ideia de identidade, salienta o autor canadense, Charles Taylor, que:

uma igualdade ambivalente utilizada para defender interesses. No caso, os argumentos da igualdade são utilizados para afirmar que não deve haver critérios diferentes para os grupos culturais, uma vez que todos têm a mesma "essência". (BACKES, 2005, p. 142).

${ }^{6}$ Ademais “o reconhecimento igualitário não é apenas a situação adequada para uma sociedade democrática saudável. A sua recusa pode prejudicar as pessoas visadas, segundo uma perspectiva moderna generalizada. [...] A projeção de uma imagem do outro como ser inferior e desprezível pode, realmente, ter um efeito de distorção e opressão, ao ponto de essa imagem ser interiorizada". (TAYLOR, 1998, p. 56-57).

Revista de Sociologia, Antropologia e Cultura Jurídica | e-ISSN: 2526-0251 | Porto Alegre | v. 4 | n. 2 |

p. $01-28$ | Jul/Dez. 2018 
[...] O desenvolvimento da noção moderna de identidade deu origem a uma política de diferença. É claro que esta política também tem uma base universalista, o que contribui para a confusão ou coincidência entre as duas políticas. Todas as pessoas devem ser reconhecidas pelas suas identidades únicas. Aqui, porém, o reconhecimento tem outro significado. Em relação à política de igual dignidade, aquilo que se estabelece visa a igualdade universal, um cabaz idêntico de direitos e imunidades; quanto a política de diferença, exige-se o reconhecimento da identidade única deste ou daquele indivíduo ou grupo, do caráter singular de cada um. Quer isto dizer, por outras palavras, que é precisamente esta singularidade que tem sido ignorada, disfarçada, assimilada a uma identidade dominante ou de maioria. (TAYLOR, 1998, p. 58).

Portanto, as diferenças definem nossa identidade e nos concedem dignidade, não nos

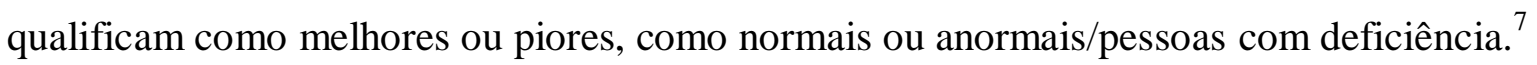

As singularidades, decorrentes da diferença, têm sido classificadas em critérios de normalidade e anormalidade, sendo que aquele que apresenta em seu corpo algum impedimento físico, mental, intelectual e sensorial, por exemplo, além de ser taxado por valores sociais preconceituosos e estigmatizantes, são desconsiderados como possuidores de identidade. Não há dúvida que a diversidade é parte da essência da espécie humana e, assim, quando alguém tem alguma deficiência física, sensorial ou intelectual, bem como quando tem marcas estéticas que não são comuns, isso deve ser visto como uma característica de nossa humanidade (e não um critério "classificador" de pessoa - a deficiência ou diferença estética não pode ser vista antes do ser humano que a tem).

Então, diante dessa natureza humana diversa, o direito à diferença contribui para uma reflexão acerca da impossibilidade de homogeneização/padronização do ser humano. Bittar enxerga que

O direito à diferença é uma ampliação, no interior da cultura do direito, da afirmação de formas de luta por reconhecimento. A ampliação elástica do conceito de direito, para abranger também a ideia de um direito à diferença, consolida a ambição de diferenciação, dentro de sociedades modernas que tendem a produzir homogeneização e padronização. É de modo reativo, portanto, que a luta pela diferença se inscreve, dialeticamente, ao lado da identidade de uma luta não interrompida por igualdade. (BITTAR, 2009, p. 553).

A igualdade e a diferença encetam duas faces de uma mesma moeda, a preponderância de uma em detrimento da outra gera situações paradoxais, ou melhor, a

\footnotetext{
${ }^{7}$ Neste sentido, traçando um paralelo sobre os três desdobramentos da igualdade, bem como talvez de certa estagnação do direito à diferença, reputamos decorrer das próprias origens quanto à diferenciação, como salienta Flávia Piovesan, ao afirmar que: "o temor à diferença é fator que permite compreender a primeira fase de proteção dos direitos humanos, marcada pela tônica da proteção geral e abstrata, com base na igualdade formal, eis que o legado do nazismo pautou-se na diferença como base para políticas de extermínio, sob o lema da prevalência e da superioridade da raça pura ariana e da eliminação das demais". (PIOVESAN, 2010, p. 49).
}

Revista de Sociologia, Antropologia e Cultura Jurídica | e-ISSN: 2526-0251 | Porto Alegre | v. 4 | n. 2 | p. $01-28$ | Jul/Dez. 2018 
preservação demasiada da igualdade, olvidando-se da diferença seria o mesmo que tecer os maiores e mais belos preceitos garantísticos em um texto constitucional, sem ao menos torná-los efetivo. A medida da igualdade não é a lei, é o ser humano em sua mais autêntica diferença.

Portanto, indubitável é que embora já se tenha evoluído bastante em relação ao reconhecimento do direito à diferença, da preservação da identidade e de que toda pessoa é única, ainda há muito a ser feito para que isso seja incorporado na prática social da qual tomamos parte. Então, para complementar o estudo, no tópico a seguir tratar-se-á a respeito da diversidade enquanto essência da humanidade.

\subsection{A diversidade enquanto essência da humanidade}

As sociedades, desde seu processo de formação, apresentaram-se multifacetadas acerca sua composição humana, vez que nenhum Estado se formou de maneira isolada, adstrito da influência e da relação com os mais variados povos e culturas. A variabilidade das pessoas e a heterogeneidade de suas características é que nos constitui e nos determina como seres humanos.

Dessa forma, consignamos que, em razão do reconhecimento da diferença, preservar as identidades dos vários “outros" que existem num Estado é fato precursor da garantia de diversidade e reflexo da própria condição humana (entendida como a possibilidade de abertura ao Outro (ou outros), ao diferente, seja culturalmente, ideologicamente, fisicamente, mentalmente etc.).

Conforme afirmado em outra passagem, a deficiência é mais uma característica dessa diversidade humana. Então, oportuno mencionar que duas formas coexistem na maneira de ver a deficiência: através de um modelo médico, que a enxerga descontextualizada, como sendo um "problema" apenas do indivíduo e no máximo de sua família, devendo ele se esforçar para "se normalizar" e se adaptar para a vida em sociedade ou através de um modelo social, que considera a deficiência como a soma de dois fatores inseparáveis: "as sequelas existentes no corpo e as barreiras físicas, econômicas e sociais impostas pelo ambiente ao indivíduo que tem essas sequelas.”. (WERNECK, 2005, p. 27). 
Destarte, a maneira mais acertada de enxergar essa característica humana é, sem sombra de dúvida, através do modelo social $^{8}$, que considera todo contexto no qual se insere aquele que tem deficiência.

O Censo de 2010 do IBGE demonstrou que 23,9 \% dos brasileiros têm alguma deficiência (ou seja, mais de 45 milhões de pessoas) (BRASIL, 2010). No mundo a Organização Mundial de Saúde estima que $10 \%$ da população mundial apresenta deficiência (RELATÓRIO, 2012). Portanto, resta incontroverso que se trata de um número expressivo de pessoas, e que ter deficiência é ter uma de suas diferenças talvez um pouco mais perceptíveis, afinal, como já salientado, ela deve ser vista apenas como mais uma característica da diversidade humana.

Eis que, quando falamos das pessoas com deficiência, ao respeitarmos suas peculiaridades e diferenças, lutando pela sua inclusão social, estaremos garantindo a proteção da diversidade, como própria essência e condição da continuidade da humanidade.

Com efeito, Eduardo Bittar assevera que:

O direito à diferença está baseado na ideia de que todos são diferentes entre si; e, propriamente, isto é ser humano, em sua singularidade. Para conceituar a 'natureza humana', deve-se, portanto, respeitar as singularidades. Isso faz com que seja necessário assumir a complexidade da diversidade, que é a marca mais concreta da 'natureza humana'[...]. Todos temos 'algo em comum' e este 'algo em comum' tem a ver com a igual possibilidade de sermos responsáveis pelo respeito à alteridade e, por isso, considerados pertencentes à comunidade dos que fruem de direitos, na medida concreta de sua condição. Torna-se imperioso, portanto, para as sociedades contemporâneas que sejam capazes de promover e permitir o igual acesso ao reconhecimento, tendo nisto um ponto de encontro de uma comunidade organizada de cidadãos. (BITTAR, 2009, p. 555).

Contudo, apesar de atualmente ter aumentado consciência social da necessidade de se proteger a diversidade para a própria preservação do ser humano (e da condição humana), ainda vislumbramos demasiada resistência em sua aceitação.

Por vezes, a difusão da igualdade ficta, que enseja no senso comum a ideia que sejamos todos iguais, cria um círculo vicioso, em que qualquer traço que nos distancie do outro, desenquadrando-o do padrão ou modelo estabelecido, é motivo para refutar a diversidade que nos permeia. Ora, é patente que:

\footnotetext{
${ }^{8}$ O modelo social para definição da deficiência surgiu a partir da iniciativa de pessoas com deficiência, reunidas no Social Disability Moviment, na década de 1960. Esse movimento provou que a maior parte das dificuldades enfrentadas por pessoas com deficiência é resultado da forma pela qual a sociedade lida com as limitações de cada indivíduo. Ora, claro está que as sequelas físicas, intelectuais e sensoriais podem ser atenuadas ou agravadas por barreiras socioambientais.
}

Revista de Sociologia, Antropologia e Cultura Jurídica | e-ISSN: 2526-0251 | Porto Alegre | v. 4 | n. 2 | 
A diferença do outro, ainda que no outro queiramos encontrar apenas a igualdade, a igualdade que nos faz, por exemplo, comuns por sermos humanos. As multicoloridas formas de expressão do que é a diversidade humana são fundamentais à condição humana, e, por isso, compõem o leque das vastas afirmações culturais humanas. (BITTAR, 2009, p. 557).

Nossa igualdade de valor decorre de nossa existência como seres humanos, mas essa mesma igualdade nos dá o direito de sermos diferentes e únicos, que garante nossa identidade individual.

Conjecturamos que a meta constitucional da sociedade inclusiva é permeada pela garantia da diversidade, sem a qual não há condições de ser nem sequer planejada.

Vislumbramos que a inclusão é um desafio longínquo em razão da "falta uma consciência política da necessidade de se promover a plena igualdade de oportunidades a todos, de se prestigiar a diversidade e a diferença e de se estimular o exercício da solidariedade" (GOMES, 2014, p. 114), embora, como dissemos, já se tenha avançado bastante.

Reputamos que essa falta de conscientização deve-se ao próprio modelo educacional implementado no Brasil e em diversos países do mundo, em que se cria um padrão normativo e de normalidade, em que tudo que se afasta do preestabelecido deve ser expurgado, via de consequência, afasta-se a diversidade, como que todos somente podem apresentar fisicamente, esteticamente, intelectual e mentalmente de uma forma, afastando os diferentes e não permitindo que a maioria que se enquadra no padrão perca a oportunidade de conviver, compartilhar, solidarizar e respeitar o Outro que se encontra fora do padrão. ${ }^{9}$

Assim, seguimos numa breve reflexão sobre padrões e o conceito de normalidade, à luz da dignidade humana.

\section{PADRÕES E NORMALIDADE: UMA REFLEX̃̃O SOBRE A DIGNIDADE HUMANA}

\footnotetext{
${ }^{9}$ Neste sentido, alerta-nos Luiz Alberto David Araujo, sobre a necessidade de se garantir a todos a convivência com a diversidade, vez que: "a sociedade deve estar preparada para conviver com ela, dentro do mesmo espaço, respeitando as diferenças. E não podemos perder de vista que o direito ao convívio com a diferença é um direito de duas mãos: é um direito evidente das pessoas com deficiência e é um direito das pessoas que não tenham deficiência, porque vão poder aprender, conviver, desenvolver acolhimento, solidariedade, qualidades necessárias e importantes. Portanto, se é um direito desse grupo vulnerável, é também direito da maioria, entendida essa como grupo sem deficiência. Todos ganhamos (e muito) com a diferença, com o acolhimento, com o convívio com pessoas diferentes”. (ARAUJO, 2014, p. 44).
}

Revista de Sociologia, Antropologia e Cultura Jurídica | e-ISSN: 2526-0251 | Porto Alegre | v. 4 | n. 2 |

p. $01-28$ | Jul/Dez. 2018 
Num primeiro momento, fez-se imperiosa a reflexão acerca da igualdade de valor e do direito à diferença dos seres humanos. Todos devem ter reconhecida sua igual dignidade humana e devem ser igualmente respeitados na sociedade. No entanto, dissemos tudo isso sem perder de vista que faz parte dessa dignidade justamente a individualidade de cada um.

Como disse Hannah Arendt: "A pluralidade é a condição da ação humana pelo fato de sermos todos os mesmos, isto é, humanos, sem que ninguém seja exatamente igual a qualquer pessoa que tenha existido, exista ou venha a existir" (ARENDT, 2001, p. 16). (grifo nosso)

Estabelecer padrões, delimitações que enquadram certas pessoas como sendo pertencentes a categorias ou grupos, não são decorrências naturais, mas são "grupos contingentes, isto é, grupos produzidos por meio de múltiplos arranjos históricos e, como tais, podem ser alterados a qualquer momento, dependendo das relações de poder que estão em jogo". (BACKES, 2005, p. 147).

Assim, não se pode negar a época paradoxal em que vivemos, na qual, embora possa parecer óbvio que cada indivíduo é único, existe uma incansável busca por uma padronização estética e comportamental, que também pode ser traduzida como uma busca de aceitação social.

Interessante, então, notar que a escola contribui há tempos com essa procura por homogeneidade, "fabricando" alunos a partir de um modelo idealizado (e, portanto, não real), fazendo com que aquele que não se encaixa nesses padrões seja (ou se sinta) excluído do círculo comunitário. Por isso, em face de sua importância, no próximo tópico, trataremos desse processo educacional homogeneizador com mais detalhes.

Importante salientar que o respeito à dignidade da pessoa humana implica no respeito e proteção à integridade física e moral, à individualidade e espiritualidade do ser humano. A partir do reconhecimento e da positivação do princípio da dignidade da pessoa humana como fundamento de nossa República (artigo $1^{\circ}$, III da Constituição Federal), é proibido pensar na hipótese de "coisificar" o ser humano, de qualquer modo. As coisas têm preço enquanto que as pessoas têm dignidade, é a preciosa lição de Kant (2005, p. 77-78). Destarte, a afronta à individualidade, ao direito de ser diferente é também "coisificação" da pessoa e, portanto, violação da sua dignidade. 
Cumpre lembrar, uma vez mais, que a dignidade da pessoa humana foi posta pelo constituinte brasileiro como elemento sustentador no qual se apoia todo o restante do sistema (LORA ALARCON , 2004, p. 253). Em suma, é “um valor de pré-compreensão de todo arcabouço jurídico do Estado brasileiro" (LORA ALARCON, 2003, p. 450). Impossível deixar de mencionar que, para Ingo Wolfgang Sarlet, a dignidade da pessoa humana pode ser definida como sendo:

[...] a qualidade intrínseca e distintiva de cada ser humano que o faz merecedor do mesmo respeito e consideração por parte do Estado e da comunidade, implicando, neste sentido, um complexo de direitos e deveres fundamentais que assegurem a pessoa tanto contra todo e qualquer ato de cunho degradante e desumano, como venham a lhe garantir as condições existenciais mínimas para uma vida saudável, além de propiciar e promover sua participação ativa e corresponsável nos destinos da própria existência e da vida em comunhão com os demais seres humanos. (SARLET, 2002, p. 62) (grifo nosso)

Podemos observar que essa definição é completa no sentido de que traz a vertente negativa (dever não agir de forma afrontosa à dignidade da pessoa humana) e a vertente positiva (obrigação de propiciar e promover a dignidade da pessoa humana).

Relavante trazer, nesse sentido, o ensinamento de Antonio Enrique Pérez Luño (2003, p. 318), no qual se vê que a dignidade da pessoa humana agrega a afirmação positiva do pleno desenvolvimento da personalidade de cada indivíduo:

La dignidad humana constituye no sólo la garantía negativa de que la persona no va a ser objeto de ofensas o humillaciones, sino que entrañatam bién la afirmación positiva del pleno desarrollo de la personalidad de cada individuo. ${ }^{10}$ (grifos nosso)

Outrossim, fica a questão: como formar e preservar uma personalidade individual quanto tudo a nossa volta tenta fazer com que estejamos de acordo com um "padrão de normalidade"? Tarefa hercúlea construir e se sentir seguro da individualidade, da fuga dos padrões estabelecidos como "normais", enfim, do reconhecimento e valorização de que a dignidade humana pressupõe esse direito de ser diferente, de ser único.

É de se perceber que o ser humano, como ser social, também exercita sua dignidade humana através de seus relacionamentos com outros indivíduos. Daí a importância da inclusão das minorias e grupos vulneráveis. Roberto Francisco Daniel faz elucidativa afirmação:

\footnotetext{
${ }^{10}$ A dignidade humana constitui não só a garantia negativa de que a pessoa não vá ser objeto de ofensas ou humilhações, mas também a afirmação positiva de pleno desenvolvimento da personalidade de cada indivíduo. (traduzimos livremente).
}

Revista de Sociologia, Antropologia e Cultura Jurídica | e-ISSN: 2526-0251 | Porto Alegre | v. 4 | n. 2 |

p. $01-28$ | Jul/Dez. 2018 
O ser estranho, o diferente é um sinal da liberdade humana. A aceitação do ser diferente do outro significa seu reconhecimento como pessoa. Assim surge uma enriquecedora ambivalência antropológica: através de sua personalidade e socialização o ser humano possui o direito de ser diferente, este direito, por sua vez, se fundamenta no que há de semelhante entre os seres humanos, ou seja, no ser pessoa. (grifos nossos) (DANIEL, 2003, p. 561).

Resta evidente, outrossim, que o direito fundamental à diferença também tem como finalidade à proteção da dignidade humana e que a diversidade no meio social é, além de enriquecedora, necessária (já que é da essência da espécie humana).

\subsection{Padrões estabelecidos e a afronta à dignidade humana}

Em outro passo, oportuno agora refletir sobre o significado de padrão e, posteriormente, de normalidade. O dicionário Houaiss ${ }^{11}$ define a palavra "padrão" da seguinte maneira:

\section{substantivo masculino}

1 base de comparação, alo que o consenso geral ou determinado órgão oficial consag rou como um modelo aprovado [...];

2 objeto que possui o tamanho e a forma mais comuns e usuais, em seu gênero; mod elo, tipo [...];

3 qualquer objeto que serve de modelo para outro [...];

4 desenho decorativo em tecido ou noutro material (azulejo, papel de parede, tapete etc.); pinta;

5 regra ou princípio us. como base de julgamento [...];

6 nível normal, grau médio de exigência qualitativa ou quantitativa; gabarito [...];

7 coisa estabelecida por autoridade como regra para medida de quantidade, peso, comprimento, valor

ou quantidade $[\ldots]$;

8 peso legalmente fixado do metal us. em moedas, nos sistemas monetários de base metálica;

9 título (no sentido de 'documento') autêntico;

10 FON configuração nítida, coerente e simétrica formada pela

rede opositiva dos fonemas de uma língua;

11 LING modelo de uma estrutura da língua ( $p$.

ex, da frase, do vocábulo etc.); esquema.

Por sua vez, o dicionário Michaelis ${ }^{12}$ assim define o termo "padrão":

sm

1 Aquilo que serve como regra para medidas de peso, valor, comprimento ou quantidade, oficialmente estabelecida por autoridade: [...].

2 Modelo estabelecido cuja aprovação por consenso geral ou por autoridade oficial serve de base de comparação; standard.

\footnotetext{
${ }^{11}$ Cf.: https://houaiss.uol.com.br/pub/apps/www/v3-0/html/index.htm\#1Acesso em: 04 maio 2018.

${ }^{12}$ Cf.: http://michaelis.uol.com.br/busca?r=0\&f=0\&t=0\&palavra=padr\%C3\%A3o. Acesso em: 04 maio 2018.
}

Revista de Sociologia, Antropologia e Cultura Jurídica | e-ISSN: 2526-0251 | Porto Alegre | v. 4 | n. 2 |

p. $01-28$ | Jul/Dez. 2018 
3 Aquilo que tem forma, tamanho, dimensões mais comuns em sua categoria ou em seu gênero; modelo, tipo: [...].

4 Qualquer objeto ou formato a ser usado ou imitado como modelo; protótipo: Esta construtora foi a primeira a customizar apartamentos, dando início a um novo padrão de prédios.

5 Nível médio de exigência tanto de qualidade como de quantidade; gabarito: [...].

6 POR EXT, FIG Grau de qualidade; categoria, classe, nível: [...].

7 Desenho de estamparia decorativa em tecido, azulejo, papel etc.; padronagem: [...].

8 GRÁF V folha de padrão.

9 Título autêntico (documento).

10 Nos antigos sistemas monetários de base metálica, peso do metal usado em moedas.

Dessas definições fica clara a ideia de que o padrão (ou os padrões) está ligado ao consenso, à percepção do que é comum, do que é modelo de comparação a partir de uma maioria. Porém, indubitável que não se pode aceitar um "padrão de pessoa", uma vez que isso é impossível em face da singularidade de cada ser humano. Como já fora dito anteriormente, a individualidade é parte da dignidade humana e, portanto, não pode ser desconsiderada. Ademais, inolvidável que fazemos parte de um Estado Democrático de Direito e que a democracia pressupõe também respeito às minorias.

Vale frisar que, apesar do que fora explanado até aqui, é cediço que o mundo impõe padrões estéticos e comportamentais. Em relação à padronização estética, Augusto Cury (2005, p. 5) lança a expressão "Padrão Inatingível de Beleza" para identificar o padrão imposto na atualidade. Esse autor faz o seguinte alerta:

Vivemos aparentemente na era do respeito pelos direitos humanos, mas, por
desconhecermos o teatro de nossa mente, não percebemos que jamais esses direitos
foram tão violados nas sociedades democráticas. Estou falando da terrível ditadura
que oprime e destrói a autoestima do ser humano: a ditadura da beleza. Apesar se
serem mais gentis, altruístas, solidárias e tolerantes do que os homens, as mulheres
têm sido o alvo preferencial dessa dramática ditadura. Cerca de 600 milhões de
mulheres sentem-se escravas nessa masmorra psíquica. É a maior tirania de todos os
tempos e uma das mais devastadoras da saúde psíquica.

Evidente, portanto, que por ser contrária à natureza humana, quando se procura a padronização estética, é inevitável a violação da dignidade e de parte da identidade pessoal. Por que o que é belo e o que é feio devem ser ditados, escolhidos "por outrem e não por mim"? Por que, numa sociedade em que se tem como princípio e fundamento a dignidade humana, não se pode escolher livremente, fora dos padrões, fora do senso comum, sem que, com isso, haja exclusão social, fixação de estereótipo e/ou discriminação?

Como exemplo hodierno dos malefícios de padronizar esteticamente, cabe aqui registrar as palavras de Naomi Wolf (1992, p. 240), que ressaltam o quanto a ditadura da 
magreza e a busca por um "Padrão Inatingível de beleza" são prejudiciais ao ser humano e, em especial, às mulheres.

\begin{abstract}
A seita da perda de peso recruta mulheres desde cedo, e os distúrbios da nutrição são seu legado. A anorexia e a bulimia são doenças do sexo feminino. Noventa a $95 \%$ dos pacientes são mulheres. Os Estados Unidos, que têm o maior número de mulheres de sucesso na esfera masculina, também lideram o mundo na incidência de anorexia feminina. As revistas para mulheres revelam que há até um milhão de americanos com anorexia, mas a Associação Americana de Bulimia e Anorexia declara que essas duas condições atacam um milhão de americanas a cada ano; e que 30.000 também estão viciadas no uso de eméticos. A cada ano, de acordo com a associação, 150.000 americanas morrem de anorexia. Se for assim, a cada doze meses, ocorrem só nos Estados Unidos 17.024 mortes a mais do que o total de mortes causadas por AIDS compilado pela Organização Mundial de Saúde em 177 países e territórios, desde o início da epidemia até o final de 1988. Se for assim, morrem mais pessoas de anorexia nos Estados Unidos a cada ano do que morreram nos dez anos de guerra Civil em Beirute.
\end{abstract}

Não há como negar a violação da dignidade humana quando se impõe à pessoa um "tratamento dos campos de concentração" para que se atinja um ideal de beleza. Não é demais afirmar que milhões pessoas estão "aprisionadas" nesses "campos de tortura psicológica", ainda que inconscientemente.

Assim, é urgente que se revejam esses padrões estabelecidos, que têm por base um ser humano idealizado, fantasioso, e que a busca de homogeneização são contrários à natureza humana.

\title{
2.2 O que é ser normal?
}

Importante, agora, notar que a ideia de padrão, de senso comum, está ligada a ideia de normalidade. Então, pergunta-se: o que é ser normal?

Oportunas, destarte, as definições dos dicionários. Primeiramente trazemos a definição de normalidade encontrada no Dicionário de Filosofia, de Nicola Abbagnano, para quem "normal" significa

1. Aquilo que está em conformidade com a norma. 2. Aquilo que está em conformidade com um hábito, com um costume, com Lima média aproximada ou matemática, ou com o equilíbrio físico ou psíquico. Neste sentido, diz-se, p. ex. levar vida N.", para dizer uma vida segundo os costumes de certo grupo social, ou "tem peso N." ou " altura N.", para dizer que tem peso ou altura correspondentes à média dos indivíduos da mesma idade, raça, etc, ou " mente N.", "um organismo N.", para indicar a boa saúde mental ou física. Este uso do termo não é completamente impróprio porque, embora as normas às quais se refere sejam obtidas

Revista de Sociologia, Antropologia e Cultura Jurídica | e-ISSN: 2526-0251 | Porto Alegre | v. 4 | n. 2 | p. $01-28$ | Jul/Dez. 2018 
de generalizações empíricas, são empregadas como critério de juízo e estabelecem uma "normalidade". (ABBAGNANO, 2007, p. 717).

No mesmo sentido a definição do Dicionário Michaelis ${ }^{13}$ :

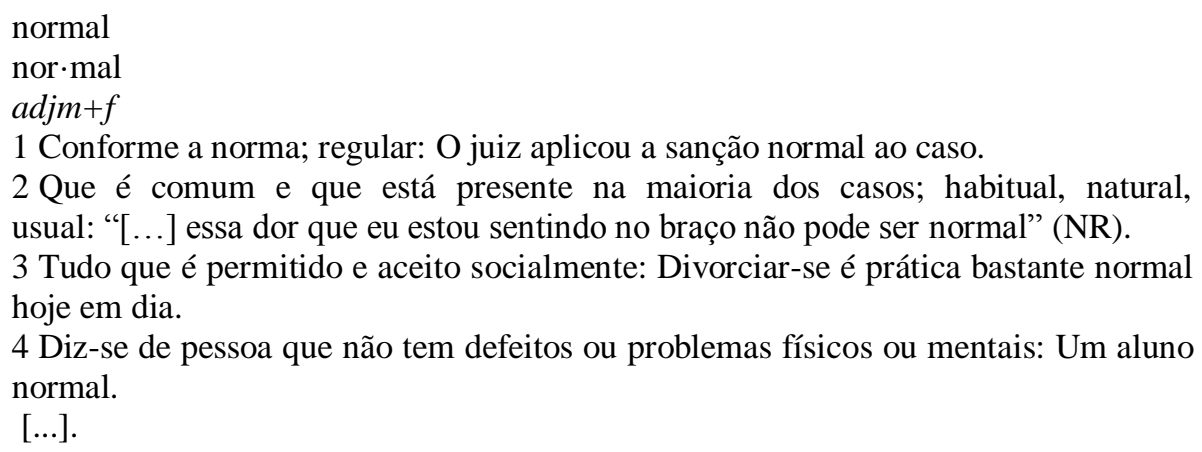

Salta aos olhos a definição de número 4, quando fala em "pessoa que não tem defeitos ou problemas físicos ou mentais". Com a devida vênia, embora isso reflita o pensamento da sociedade (que é despreparada para lidar com as diferenças), indaga-se: existe realmente alguém que não tenha defeitos ou problemas físicos ou mentais? Não seriam nossos defeitos (genéticos ou adquiridos) uma comprovação da nossa humanidade?

A ideia de normalidade, como se vê em ambos os dicionários, também se mostra no que é comum, habitual, usual e, com convicção, afirmamos que a diversidade é a regra na humanidade. Todos somos diferentes e únicos, apesar de termos o mesmo valor enquanto seres humanos. Assim, a diversidade é habitual e a diferença é usual, embora seu reconhecimento não seja. Talvez tenha razão Caetano, quando cantou que "de perto ninguém é normal". 14

É de bom alvitre observar, então, que normalidade não é um conceito que exclua as pessoas com deficiência, como já se demonstrou em tópico anterior, uma vez que são grande parcela da população mundial e quase um quarto da população brasileira. Aliás, com o aumento da expectativa de vida do brasileiro, cresce também o número de deficiências adquiridas ao longo da vida, por uma degradação natural do organismo. Por isso, aceitar, respeitar e conviver com as diferenças significa colaborar com a construção da sociedade que desejamos que nos receba em nossa velhice.

Todavia, válido ressaltar que:

\footnotetext{
${ }^{13}$ Cf.: http://michaelis.uol.com.br/busca?r=0\&f=0\&t=0\&palavra=padr\%C3\%A3o Acesso em 04 maio 2018.

${ }^{14}$ Caetano Veloso, em sua música "Vaca Profana", afirma algo que é de sabedoria popular: "de perto ninguém é normal". (VELOSO, 1986)
} 
pelo menos, desde o século XV um ideal normativo de homem médio é estabelecido como no modelo vitruviano, e posteriormente, no século XIX, tal ideal é transformado e reforçado em parâmetros científicos antropométricos de normalidade, que são utilizados desde então como referenciais para a construção dos espaços sociais. Todos os indivíduos que não se encaixam nestes padrões, como crianças, idosos, gestantes e pessoas com deficiência física ou motora, auditiva, visual, intelectual, múltipla, entre outros, ficam restritos à possibilidade de acesso e usufruto destes espaços e das relações que aí se desenvolvem. Assim, tais pessoas apesar de representarem parcela significativa da população, serem expressão da diversidade humana e de diferentes momentos e modos de vida - têm suas especificidades e características desconsideradas na organização cotidiana do espaço social. (MUNHOZ, 2014, p. 137)

É interessante também trazer a posição acertada de Carlos Skliar sobre a deficiência: "não é uma questão biológica e sim uma retórica social, histórica e cultural. A deficiência não é um problema dos deficientes ou de suas famílias ou dos especialistas. A deficiência está relacionada com a própria ideia da normalidade e com sua historicidade.” (SKILIAR, 1999, p. $18)$.

Em razão de tudo isso, este estudo quer levar o leitor à reflexão para a desconstrução do senso comum sobre o que é ser normal, bem como para o entendimento de que o estabelecimento de padrões para seres humanos é algo contrário à natureza e violador da dignidade humana, na medida em que desprestigia a individualidade de cada um.

Imperativa, destarte, é a conclusão de que "ser diferente é normal". ${ }^{15}$ 15 Slogan de Campanha do Instituto Meta Social, que também virou título da música composta por Adilson Xavier e
Vinícius Castro:
Todo mundo tem seu jeito singular
De ser feliz, de viver e enxergar
Se os olhos são maiores ou são orientais
E daí, que diferença faz?
Todo mundo tem que ser especial
Em oportunidades, em direitos, coisa e tal
Seja branco, preto, verde, azul ou lilás
E daí, que diferença faz?
Já pensou, tudo sempre igual
Ser mais do mesmo o tempo todo não é tão legal
Já pensou, tudo sempre tão igual?
Tá na hora de ir em frente:
Ser diferente é normal!
Ser diferente é normal!
Ser diferente é normal!
Todo mundo tem seu jeito singular
De crescer, aparecer e se manifestar
Se o peso na balança é de uns quilinhos a mais
E daí, que diferença faz?
Todo mundo tem que ser especial
Em seu sorriso, sua fé e no seu visual 


\section{O PAPEL DA ESCOLA NA CONSTRUÇÃO/DESCONSTRUÇÃO DOS PADRÕES HOMOGENEIZADORES}

Ensinou Paulo Freire que "a educação se desenvolve na História, nasce na História e se transforma historicamente, assim como nós nos construímos historicamente e não apenas geneticamente.” (FREIRE, 2014, p. 28). Na História da Educação no Brasil percebe-se que a educação escolar sempre foi elitista, segregacionista, de baixa qualidade, utilitarista, enfim, fez-se a escola brasileira "para alguns" e não para todos. (SEGALLA, 2015, p. 24).

Hoje a educação escolar, tal como antes, ainda é de certa forma elitista, excludente, utilitarista (FREIRE, 2014, p. 77). e muito mais preocupada com a qualificação para o mercado de trabalho, em detrimento da formação e do desenvolvimento humano (embora não se possa negar que já evoluímos bastante).

Contudo, não se pode perder a esperança: ainda acreditamos na educação como uma importante ferramenta de transformação social, como coloca Lauro Ribeiro: "a educação é o mais significativo instrumento de justiça social, para corrigir as desigualdades provenientes da posição de riqueza.”. (RIBEIRO, 2009, p. 67). (grifos nossos)

Com a promulgação da Constituição Federal de 1988 tem-se que a educação visa o pleno desenvolvimento humano, o preparo para o exercício da cidadania e para o trabalho. É isso que determina o caput de seu artigo 205.

Destarte, pode-se concluir que a educação almejada pelo Constituinte de 1988 vai muito além do seu aspecto cognitivo, uma vez que o pleno desenvolvimento humano e a preparação para o exercício da cidadania ultrapassam esse limite.

\footnotetext{
Se curte tatuagens ou pinturas naturais

E daí, que diferença faz?

Já pensou, tudo sempre igual?

Ser mais do mesmo o tempo todo não é tão legal

Já pensou, tudo sempre igual?

Tá na hora de ir em frente:

Ser diferente é normal

Sha-na-na $\} 12 x$

Disponível em: http://letras.bandas.mus.br/lenine/ser-diferente-e-normal Acesso em 05.maio.2018.
}

Revista de Sociologia, Antropologia e Cultura Jurídica | e-ISSN: 2526-0251 | Porto Alegre | v. 4 | n. 2 |

p. $01-28$ | Jul/Dez. 2018 
Não é novidade que a escola brasileira está deixando a desejar e evidente é a necessidade de reformulá-la ${ }^{16}$. Talvez, então, começar com uma postura inclusiva seja uma boa alternativa no caminho para a qualidade do ensino: boa para todos (e não só para os alunos que têm deficiência).

É necessário desconstruir a ideia de um padrão ideal do alunado. Não é à toa que dissemos que a escola "fabrica" e estimula a homogeneização, quando estabelece um "padrão de normalidade" de aprendizagem para todos os alunos ou quando trata igualmente todos os alunos, desconsiderando suas peculiaridades. Ora, se todos os alunos são diferentes, como esperar que, apesar de cada um ser dotado de habilidades e capacidades, todos são obrigados a ter um desempenho satisfatório que corresponda a um "padrão de normalidade" em todas as disciplinas que lhes são ensinadas?

A escola também sempre foi responsável por estimular à concepção de um padrão estético ideal, seja quando não valoriza a diversidade e a individualidade, seja quando não coíbe a prática de "bullying" ou de qualquer ato que desrespeite a dignidade humana. As crianças começam a construção do que é normal e do que é anormal também no ambiente escolar.

Aprender em meio às diferenças é saudável e estimulante. Sem dúvida é assim que se prepara NA cidadania para o exercício DA cidadania e para o pleno desenvolvimento humano.

Ninguém consegue se desenvolver plenamente se não a partir de sua sociabilização num contexto real, ou seja, num ambiente que reflete as diferenças como características humanas. Outra qualidade do ser humano, como já visto, é que somos eminentemente sociais e carecemos de vínculos afetivos. Precisamos do outro e o outro precisa de nós, inevitavelmente. Então, na escola é possível tanto ensinar e vivenciar quanto negligenciar a solidariedade.

No ambiente escolar é que se tem a possibilidade de desde cedo, ao conviver com a diversidade, aprender a entender, respeitar e tratar com respeito e naturalidade àquele que é diferente do seu "eu".

\footnotetext{
${ }^{16}$ Maria Teresa Eglér Mantoan diz: "A Escola brasileira é marcada pelo fracasso e pela evasão de uma parte significativa de seus alunos, marginalizados pelo insucesso, por privações constantes e pela baixa autoestima resultante das exclusões escolar e social [...]. A inclusão total e irrestrita é uma oportunidade que temos para reverter a situação da maioria de nossas escolas [...]". (MANTOAN, 2006, p. 21).
} 
Em suma, diante de todo exposto, resta evidente a importância da escola na construção/desconstrução dos padrões homogeneizadores.

\title{
3.1 Escola versus linha de montagem
}

Como se enfatizou acima, a escola deveria ser um ambiente acolhedor das diferenças, de maneira que estimulasse a capacidade e o desenvolvimento de cada um. Porém, o que se percebe ainda hoje é que parece que seu papel é de massificação, de padronização de pessoas. Essa constatação não é de nossa autoria, mas de educadores ${ }^{17}$ comprometidos com a Educação e com a sociedade.

Mencionam-se, como exemplo, as palavras de Rubem Alves:

\begin{abstract}
Nossas escolas são construídas segundo o modelo das linhas de montagem. Escolas são fábricas organizadas para a produção de unidades biopsicológicas móveis, portadoras de conhecimento e habilidades. Esses conhecimentos e habilidades são definidos exteriormente por agências governamentais a que se conferiu autoridade para isso. Os modelos estabelecidos por tais agências são obrigatórios, e têm a força de leis. Unidades biopsicológicas móveis que, ao final, do processo, não estejam de acordo com tais modelos são descartadas. É a sua igualdade que atesta a qualidade do processo. Não havendo passado no teste de qualidade-igualdade, elas não recebem os certificados de excelência ISO-12.000, vulgarmente denominados diplomas. As unidades biopsicológicas móveis são aquilo que vulgarmente recebe o nome de "alunos". (ALVES, 2001, p. 36)
\end{abstract}

Ilustrando a crítica de Rubem Alves, acerca dos alunos serem colocados em "linhas de montagem", registra-se o caso da Prefeitura do Rio de Janeiro, que lançou uma propaganda com foto de crianças numa esteira de produção, com a seguinte chamada: "Nossa linha de produção é simples. Construímos escolas, formamos cidadãos e criamos futuros". A imagem gerou grande repercussão em uma rede social, o que acabou sendo noticiado pela mídia, como se pode observar no Anexo A, e merece nossa reflexão, pois parece que o Poder Público do Rio de Janeiro estava explicitamente tratando a escola como um centro de "produção de alunos" (e alunos iguais).

$\mathrm{Na}$ prática educacional da escola brasileira, desde o princípio da História da Educação no Brasil (SEGALLA, 2015, p. 24-56), percebe-se que existe sim um "fábrica de alunos" em detrimento das potencialidades e individualidades, a qual desconsidera a diversidade enquanto característica da espécie humana.

\footnotetext{
${ }^{17}$ Como exemplos temos os autores Rubem Alves e Maria Teresa Eglér Mantoan.
} 


\subsection{A escola e a transformação social}

Temos que: “A escola é o começo de tudo. Se ela não alterar seus princípios, adeus sociedade inclusiva [...]. Escola só é escola se for transformadora" (WERNECK, 2001, p. 61) (grifo nosso). Ao fazer tal afirmação, Claudia Werneck ainda complementa sua ideia sobre a missão da escola dizendo que "os princípios da inclusão nada mais são do que os princípios da democracia” (WERNECK, 2001, p. 61). A Educação é, sem dúvida, o principal caminho para a transformação social, para mudança do status quo. Da mesma forma em que os padrões de homogeneização podem ser construídos na escola, nela também é possível fazer o movimento inverso, de desconstrução.

Paulo Freire, que vê o ser humano como um ser inacabado, afirma que nossa educabilidade decorre de nossa inconclusão (FREIRE, 1996, p. 28). Em suas palavras: "Ninguém nasce feito. Vamos nos fazendo aos poucos, na prática social de que tomamos parte" (FREIRE, 2001, p. 40) (grifo nosso). Por isso, nossa proposta é para que o leitor nos acompanhe nessa batalha por uma escola inclusiva (ou seja, que uma escola que receba a todos), que não seja homogeneizadora, mas que consiga potencializar e desenvolver ao máximo as capacidades individuais de cada aluno, ensinando, para além do aspecto cognitivo, lições para o exercício da cidadania e para a construção de uma sociedade mais justa, livre e solidária, sem preconceitos ou discriminações, conforme almejou o Constituinte de 1988 (artigo $3^{\circ}$ da Constituição Federal).

Freire ensina também que: "Este é também um direito e um dever dos cidadãos [...]: o de se baterem por uma escola mais democrática, menos elitista, menos discriminatória [...]. Uma escola aberta, que supere preconceitos, que se faça um centro de alegria [...]" (FREIRE, 2001, p. 13) (grifos nossos). Em outras palavras: uma escola para todos, que respeita a igualdade e valoriza a diversidade.

Por fim, destacamos que, embora não haja "solução mágica", nem resposta prática fácil e rápida, acredita-se que a mudança é possível e começa em cada um de nós.

\section{CONCLUSÕES}

Revista de Sociologia, Antropologia e Cultura Jurídica | e-ISSN: 2526-0251 | Porto Alegre | v. 4 | n. 2 |

p. $01-28$ | Jul/Dez. 2018 
Restou evidente, diante de todo o exposto, que o direito à igualdade e o direito à diferença são "faces da mesma moeda" e tanto um quanto outro são assegurados pelo ordenamento jurídico brasileiro. Todos somos iguais em nossa humanidade e, ao mesmo tempo, temos direito de sermos respeitados em nossa individualidade.

Ademais, a diversidade faz parte da essência humana: a diferença é característica da humanidade. Aliás, são as diferenças que preservam nossa identidade.

Incontroverso, também, que a tentativa de "padronização humana", como violadora da dignidade humana, já que uma de suas vertentes é justamente a individualidade.

Além disso, demonstramos o equívoco de se tentar encontrar um "padrão de normalidade" entre os seres humanos, uma vez que isso não é natural diante de tanta diversidade. Ficou claro que, dentre as características peculiares de cada um, a deficiência não pode ser vista como "antônimo" de normalidade, pois ser diferente é normal.

Por fim, indubitável é que a escola tem um papel fundamental na sociedade: seja para manutenção do status quo, de busca pela homogeneização, seja para transformação social, na desconstrução de paradigmas que são contrários à natureza humana.

A escola deve, conforme determinação constitucional, objetivar o pleno desenvolvimento humano e a preparação para o exercício da cidadania, além da preparação para o trabalho. Assim, muito além do seu aspecto cognitivo, tem o dever de contribuir para a construção de uma sociedade livre, justa e solidária.

Convém registramos que nossa esperança de que essa transformação aconteça, mas é necessário termos a consciência de que a mudança só será possível se a escola receber e valorizar a diversidade humana.

\section{REFERÊNCIAS}

ABBAGNANO, Nicola. Dicionário de Filosofia. 5. ed. São Paulo: Martins Fontes, 2007.

ALVES, Rubem. A escola com que sempre sonhei sem imaginar que pudesse existir. Campinas: Papirus, 2001.

ARAUJO, Luiz Alberto David. Artigo 3 - Princípios Gerais. DIAS, Joelson; FERREIRA, Laíssa da Costa; GUGEL, Maria Aparecida; COSTA FILHO, Waldir Macieira da (Org.). Novos Comentários à Convenção Internacional sobre os Direitos das Pessoas com Deficiência. Brasília: Secretaria de Direitos Humanos - SDH. Secretaria Nacional de Promoção dos Direitos da Pessoa com Deficiência - SNPD, 2014. 
Andréia Garcia Martin \& Juliana Izar Soares da Fonseca Segalla

ARENDT, A condição humana. 10. ed. Rio de Janeiro: Forense Universitária, 2001.

BACKES, José Licínio. A negociação das identidades/ diferenças culturais no espaço escolar. São Leopoldo: UNISINOS, 2005. (Tese de doutorado), 2005.

BITTAR, Eduardo Carlos Bianca. Reconhecimento e direito à diferença: teoria crítica, diversidade e a cultura dos direitos humanos. Revista da Faculdade de Direito da Universidade de São Paulo, v. 104 p. 551 - 565 jan./dez. 2009.

BOBBIO, Norberto. A era dos direitos. Rio de Janeiro: Campus, 1997.

CANDAU, Vera Maria. Direitos humanos, educação e interculturalidade: as tensões entre igualdade e diferença. In: Revista Brasileira de Educação, n 37, 2008.

CAVALCANTI, Ana Carolina Coutinho Ramalho. Artigo 8 - Conscientização. DIAS, Joelson; FERREIRA, Laíssa da Costa; GUGEL, Maria Aparecida; COSTA FILHO, Waldir Macieira da (Org.). Novos Comentários à Convenção Internacional sobre os Direitos das Pessoas com Deficiência. Brasília: Secretaria de Direitos Humanos - SDH. Secretaria Nacional de Promoção dos Direitos da Pessoa com Deficiência - SNPD, 2014.

CURY, Augusto Jorge. A ditadura da beleza e a revolução das mulheres. Rio de Janeiro: Sextante, 2005.

DANIEL, Roberto Francisco. Ser pessoa: a base ontológica do direito. In: ARAUJO, Luiz Alberto David (Coord.). Efetivando direitos constitucionais. Bauru: EDITE, 2003.

FREIRE, Paulo. Pedagogia da autonomia: saberes necessários à prática educativa. 25. ed. São Paulo: Paz e Terra, 1996.

FREIRE, Paulo. Pedagogia da solidariedade. São Paulo: Paz e Terra, 2014.

FREIRE, Paulo. Política e educação. 5. ed. São Paulo: Cortez, 2001.

GOMES, Lauro Ribeiro. Artigo 16 - Prevenção contra a exploração, a violência e o abuso. DIAS, Joelson; FERREIRA, Laíssa da Costa; GUGEL, Maria Aparecida; COSTA FILHO, Waldir Macieira da (Org.). Novos Comentários à Convenção Internacional sobre os Direitos das Pessoas com Deficiência. Brasília: Secretaria de Direitos Humanos - SDH. Secretaria Nacional de Promoção dos Direitos da Pessoa com Deficiência - SNPD, 2014.

HALL, Stuart. Da Diáspora: identidades e mediações culturais. Tradução Adelaide La Guardia Resende, Ana Carolina Escosleguy, Cláudia Àlvares, Francisco Rüdiger e Soyonara Amaral. Belo Horizonte: UFMG, 2003.

MANTOAN, Maria Teresa Eglér. Inclusão escolar: o que é? Por quê? Como fazer? 2. ed. São Paulo: Moderna, 2006.

Revista de Sociologia, Antropologia e Cultura Jurídica | e-ISSN: 2526-0251 | Porto Alegre | v. 4 | n. 2 |

p. $01-28$ | Jul/Dez. 2018 
MUNHOZ, Antônio Carlos "Tuca"; PAULA, Ana Rita de; CAVALHEIRO, Andrea de Moraes. Artigo 20 - Mobilidade pessoal. DIAS, Joelson; FERREIRA, Laíssa da Costa; GUGEL, Maria Aparecida; COSTA FILHO, Waldir Macieira da (Org.). Novos Comentários à Convenção Internacional sobre os Direitos das Pessoas com Deficiência. Brasília: Secretaria de Direitos Humanos - SDH. Secretaria Nacional de Promoção dos Direitos da Pessoa com Deficiência - SNPD, 2014.

PIERUCCI, Antônio Flávio. Ciladas da diferença. São Paulo: Editora 34, 1999.

PIOVESAN, Flavia. Igualdade, Diferença e Direitos Humanos: Perspectiva Global e Regional. SARMENTO, Daniel; IKAWA, Daniela; PIOVESAN, Flávia (Coord.). Igualdade, Diferença e Direitos humanos. Rio de Janeiro: Lumen Juris, 2010.

RIBEIRO, Lauro Luiz Gomes, Direito educacional: educação básica e federalismo. São Paulo: Quartier Latin, 2009.

SANTANA, Joaquim; ALMEIDA, Luiz Claudio. Artigo 10 - Direito à Vida. DIAS, Joelson; FERREIRA, Laíssa da Costa; GUGEL, Maria Aparecida; COSTA FILHO, Waldir Macieira da (Org.). Novos Comentários à Convenção Internacional sobre os Direitos das Pessoas com Deficiência. Brasília: Secretaria de Direitos Humanos - SDH. Secretaria Nacional de Promoção dos Direitos da Pessoa com Deficiência - SNPD, 2014.

SANTOS, Boaventura de Sousa. A construção multicultural da Igualdade e da Diferença. Oficina do CES. n. 135 - 1999: Publicação seriada do Centro de Estudos Sociais. Praça D. Dinis. Colégio São Jerónimo, Coimbra. Disponível em: <http://www.ces.uc.pt/publicacoes/oficina/135/135.pdf>. Acesso em 05 abr. 2018.

SANTOS, Boaventura de Sousa. A gramática do tempo: para uma nova cultura política. São Paulo: Cortez, 2006.

SEGALLA, Juliana Izar Soares da Fonseca. Direito à educação, participação familiar e informação: o ciclo virtuoso da inclusão. [Tese de Doutorado]. PUC-SP, 2015.

TAYLOR, Charles. Multiculturalismo. Lisboa: Instituto Piaget, 1998.

VEIGA-NETO, Alfredo. Cultura, culturas e educação. Revista Brasileira de Educação, São Paulo, n. 23, p. 5-15, maio/jun./jul./ago. 2003.

WERNECK, Claudia. Manual sobre desenvolvimento inclusivo. Rio de Janeiro: WVA, 2005.

WERNECK, Claudia. Ninguém mais vai ser bonzinho na sociedade inclusiva. Rio de Janeiro: WVA, 2000.

WOLF, Naomi. O mito da beleza: como as imagens de beleza são usadas contra as mulheres. Rio de Janeiro: Rocco, 1992.

Revista de Sociologia, Antropologia e Cultura Jurídica | e-ISSN: 2526-0251 | Porto Alegre | v. 4 | n. 2 |

p. $01-28$ | Jul/Dez. 2018 


\section{ANEXO A \\ "Linha de montagem"}

\section{REVISTA CARTA CAPITAL}

\section{Prefeitura do Rio retrata escola como linha de produção}

Anúncio traz alunos sobre esteira mecânica e é alvo de críticas; cena remete a 'The Wall', em que crianças são jogadas em moedor de carne por Redação — publicado 08/12/2014 20:45, última modificação 09/12/2014 06:15

Um anúncio da prefeitura do Rio de Janeiro publicado na edição de domingo, 7, do jornal $O$ Globo tornou-se o centro de duras críticas nas redes sociais pelo modo como aborda o ensino: na imagem que ilustra toda a página, crianças em carteiras escolares estão dispostas sobre uma esteira mecânica como as utilizadas em fábricas. Diz o anúncio: "Nossa linha de produção é simples".

Para muitos, a visão exposta pela administração do prefeito Eduardo Paes no anúncio explora uma visão de educação massificada e opressora, indiferente às diferenças e especificidades de cada instituição e de cada criança. Fora isso, ao colocar o processo de ensino e aprendizagem como uma produção em série, esquece-se da formação humanista, geradora de autonomia e espírito crítico.

Esse ambiente foi rapidamente comparado ao de The Wall, filme do Pink Floyd do início dos anos 1980, que retrata crianças num sistema escolar opressivo, num mundo distópico, que se rebelam contra a escola e seus tutores. Em uma de suas cenas mais famosas, os alunos são encaminhados em uma esteira rumo a um moedor de carne.

Disponível em: http://www.cartacapital.com.br/blogs/parlatorio/prefeitura-do-rio-retrataescola-como-linha-de-producao-7482.html

Prefeitura do Rio compara escola à fábrica e gera críticas no Facebook

Do UOL, em São Paulo

09/12/201410h47 > Atualizada 09/12/201411h32

Revista de Sociologia, Antropologia e Cultura Jurídica | e-ISSN: 2526-0251 | Porto Alegre | v. 4 | n. 2 |

p. $01-28$ | Jul/Dez. 2018 


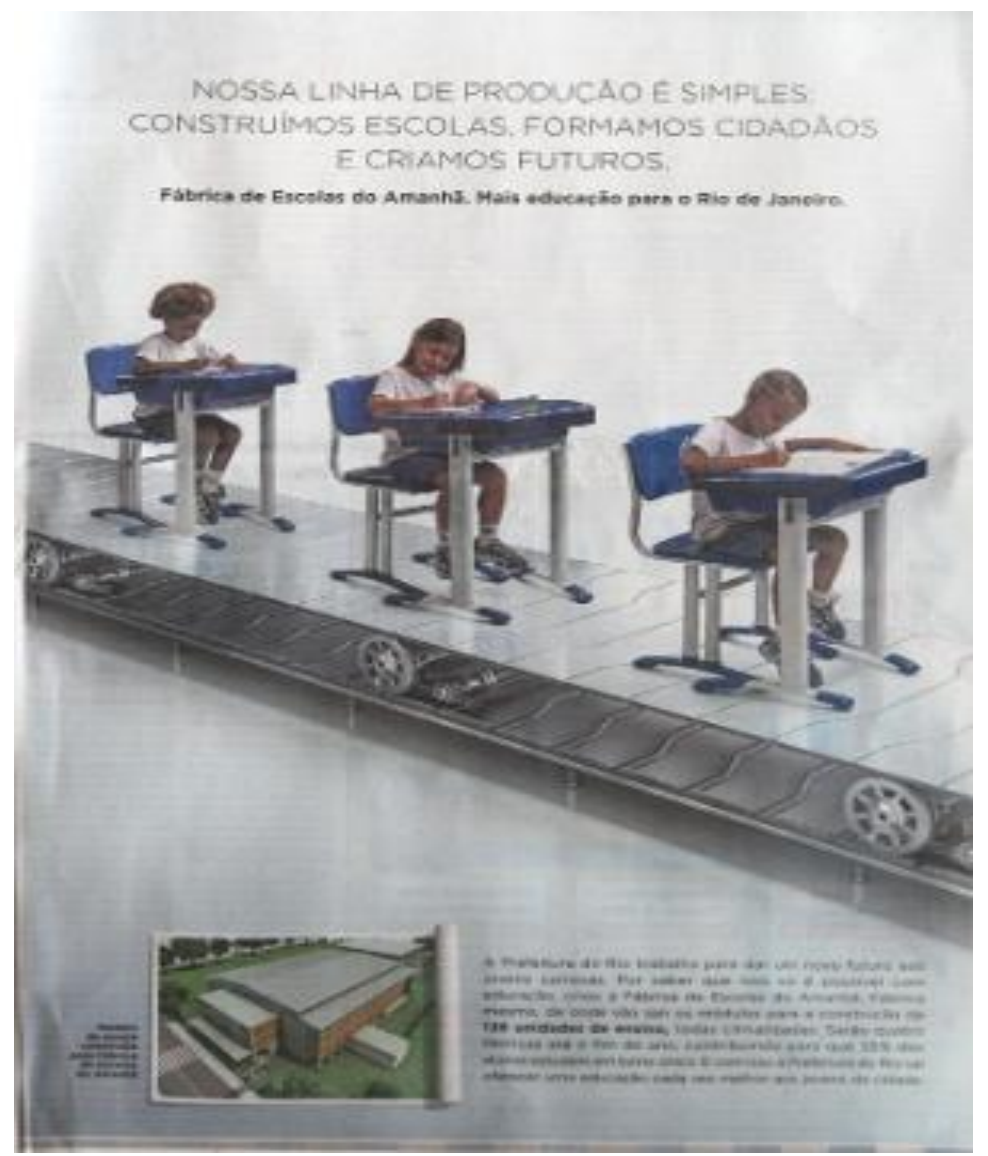

Uma propaganda da Prefeitura do Rio de Janeiro gerou polêmica nas redes sociais neste fim de semana. A peça, que foi publicada no domingo (7) no jornal "O Globo", mostra três crianças em carteiras escolas sobre uma esteira, como se estivessem na linha de produção de uma fábrica. O texto diz: "Nossa linha de produção é simples. Construímos escolas, formamos cidadãos e criamos futuros".

O texto faz referência à Fábrica de Escolas do Amanhã, unidade responsável pela construção de estruturas pré-moldadas e do armazenamento e distribuição de material para novas escolas da rede municipal de ensino.

A propaganda, porém, não foi bem recebida pelos os professores e funcionários do município, que entenderam que o material relaciona os alunos a produtos. "A imagem ilustra bem as denúncias que os professores e trabalhadores da educação pública têm feito nos últimos anos, quando indicávamos a mercantilização da educação, que cada vez mais deixa de ser um direito para se transformar em um negócio", afirma o professor Silvio Pedrosa, que dá aulas de história para alunos do $6^{\circ}$ ao $9^{\circ}$ ano na rede municipal.

O deputado estadual Marcelo Freixo (Psol) também criticou a propaganda em sua página no Facebook. "Uma escola na Ilha do Governador é diferente de uma escola na Pavuna, diferente de uma escola no Méier, no Leblon. Quando a escola recebe um projeto de cima para baixo ela fica engessada e não pode transformar a realidade, porque ela não consegue se apropriar daquela realidade em seu dia a dia escolar", afirma o deputado na rede social.

Segundo Freixo, uma educação pública de qualidade e acessível a todos e todas "só é possível com autonomia para os profissionais de educação". A publicação na página do deputado já foi curtida por mais de 8.800 pessoas e compartilhada por mais de 5.000 internautas. 
Pedrosa cita ainda que um dos lemas das greves de 2013 e 2014 era "Educação não é mercadoria". "Na imagem, está transparente a forma como os setores dirigentes da cidade do Rio de Janeiro (e arriscaria dizer em todo o Brasil) enxergam o problema da educação."

No Facebook, a publicação de Silvio sobre a propaganda da prefeitura já tinha mais de 1.400 compartilhamentos até a tarde desta segunda (8), e muitos colegas criticavam a peça publicitária. "Confesso que me surpreendi com a repercussão. Parece que há uma indignação mais ampla em relação a esse tipo de tratamento simbólico dado aos alunos e ao papel da educação na sociedade", afirma.

\section{Outro lado}

A assessoria de imprensa da Secretaria Municipal de Educação foi procurada pelo UOL na tarde de ontem (8) para comentar a repercussão da propaganda, porém até o fechamento desta matéria não houve um posicionamento do órgão. Assim que a reportagem receber uma resposta, ela será incluída no texto.

Disponível em: http://educacao.uol.com.br/noticias/2014/12/09/prefeitura-do-rio-comparaescola-a-fabrica-e-gera-criticas-no-facebook.htm 